\title{
A tea catechin, epigallocatechin-3-gallate, is a unique modulator of the farnesoid $X$ receptor
}

\author{
Guodong Lia,b, Wenwei Lin ${ }^{c}$, Juan J. Arayad, Taosheng Chenc, Barbara N. Timmermann ${ }^{d}$, \\ and Grace L. Guo ${ }^{a}{ }^{*}$ \\ aDepartment of Pharmacology, Toxicology and Therapeutics, University of Kansas Medical \\ Center, Kansas City, KS, USA \\ bDepartment of Abdominal Surgery, Cancer treatment center, Fourth Affiliated Hospital of Harbin \\ Medical University, Harbin, People's Republic of China \\ 'Department of Chemical Biology \& Therapeutics, St. Jude Children's Research Hospital, \\ Memphis, TN, USA \\ ${ }^{\mathrm{d} D e p a r t m e n t}$ of Medicinal Chemistry, University of Kansas, Lawrence, KS, USA
}

\begin{abstract}
Farnesoid X receptor (FXR) is a ligand-activated nuclear receptor and serves as a key regulator to maintain health of the liver and intestine. Bile acids are endogenous ligands of FXR, and there are increasing efforts to identify FXR modulators to serve as biological probes and/or pharmaceutical agents. Natural FXR ligands isolated from plants may serve as models to synthesize novel FXR modulators. In this study, we demonstrated that epigallocatechin-3-gallate (EGCG), a major tea catechin, specifically and dose-dependently activates FXR. In addition, EGCG induced FXR target gene expression in vitro. Surprisingly, in a co-activator (SRC2) recruitment assay, we found that EGCG does not recruit SRC2 to FXR, but it dose-dependently inhibits recruitment of SRC2 to FXR $\left(\mathrm{IC}_{50}, 1 \mu \mathrm{M}\right)$ by GW6064, which is a potent FXR synthetic ligand. In addition, EGCG suppressed FXR target gene expression induced by either GW4064 or chenodeoxycholic acid in vitro. Furthermore, wild-type and FXR knockout mice treated with an acute dose of EGCG had induced mRNA expression in a subset of FXR target genes in the intestine but not in the liver. In conclusion, EGCG is a unique modulator of FXR in the intestine and may serve as an important model for future development of FXR modulators.
\end{abstract}

\section{Keywords}

farnesoid X receptor; epigallocatechin-3-gallate; nuclear receptor; tea catechin; modulator; mice

\footnotetext{
(c) 2011 Elsevier Inc. All rights reserved.

"Corresponding author: Grace L. Guo, Ph.D., Department of Pharmacology, Toxicology and Therapeutics, University of Kansas Medical Center, 3901 Rainbow Boulevard, Kansas City, Kansas, 66160, USA., Phone: +1 913-588-0481; Fax: +1 913-588-7501; lguo@kumc.edu.

Conflict of interest statement

The authors have declared that there are no conflicts of interest.

Publisher's Disclaimer: This is a PDF file of an unedited manuscript that has been accepted for publication. As a service to our customers we are providing this early version of the manuscript. The manuscript will undergo copyediting, typesetting, and review of the resulting proof before it is published in its final citable form. Please note that during the production process errors may be discovered which could affect the content, and all legal disclaimers that apply to the journal pertain.
} 


\section{Introduction}

FXR (farnesoid X receptor, NR1H4) is a ligand-activated transcription factor and a member of the nuclear receptor superfamily. Bile acids are FXR's endogenous ligands. FXR regulates the biosynthesis and enterohepatic circulation of bile acids in addition to its regulation of triglyceride, cholesterol and glucose metabolism (Sinal et al., 2000; Cariou et al., 2005; Rizzo et al., 2005; Ma et al., 2006; Zhang et al., 2006). Recent evidence shows that FXR is also critical in maintaining innate immune responses in intestine (Vavassori et $a l .$, 2009). In addition, FXR deficiency in mice results in increased cholestasis, nonalcoholic fatty liver diseases, hepatocellular carcinoma and colon cancer (Gadaleta et al., 2010). This evidence suggests that FXR and FXR-mediated signaling pathways may be promising novel drug targets for the treatment of common metabolic diseases. However, use of synthetic FXR ligands in the clinic has not yet been approved.

The goal of the current study is to screen for FXR modulators in tea plant. Tea is a traditional medicinal plant and is also the most widely consumed beverage in the world, second only to water. The most commonly consumed teas are black, green, and oolong. These teas are all derived from the plant Camellia sinensis, which is a member of the Theaceae family. Epidemiologic and animal studies suggest that drinking green tea offers protection against cardiovascular diseases and a variety of cancers (oral cavity, esophagus, stomach, liver, small and large intestine, and mammary gland) (Setiawan et al., 2001; Zhang et al., 2002; Wu et al., 2003; Jian et al., 2004; Cabrera et al., 2006). Catechins are polyphenolic compounds and are one class of major chemicals found in tea. Examples of tea catechins include (-)-epigallocatechins-3-gallate (EGCG), (-)-epigallocatechin (EGC), (-)epicatechin-3-gallate (ECG), and (-)-epicatechin (EC) (Figure 1). EGCG is the major constituent and the most biologically active catechin of green tea. Numerous studies report that EGCG can lower oxidative stress, atherosclerosis, inflammation, and cholesterol (Dona et al., 2003; Frei and Higdon, 2003; Raederstorff et al., 2003; Chyu et al., 2004). However, no effect of tea compounds on FXR activity has been reported. Therefore, we aimed to determine the effects of tea catechins, particularly EGCG, in modulating FXR activity in this study.

\section{Materials and Methods}

\section{Chemicals}

Thirty-four commercially available samples of green tea $(5 \mathrm{~g})$ were extracted with $10 \mathrm{~mL}$ of $\mathrm{H}_{2} \mathrm{O}\left(70^{\circ} \mathrm{C}\right.$, for $\left.10 \mathrm{~min}\right)$ to simulate conditions of regular infusion. The resulting aqueous extracts were concentrated in vacuo and dried overnight at $30^{\circ} \mathrm{C}$ in a vacuum oven. All plant samples were prepared at the Department of Medicinal Chemistry, University of Kansas Lawrence. GW4064 was synthesized by the Department of Medicinal Chemistry, University of Kansas. Chenodeoxycholic acid (CDCA), ECG, EGC, and EGCG were purchased from Sigma-Aldrich (St. Louis, MO). All compounds and catechins were dissolved in DMSO for in vitro studies. For the in vivo study, EGCG was dissolved in $0.9 \%$ saline and stored at $-20^{\circ} \mathrm{C}$.

\section{Cell culture}

Human hepatocellular carcinoma cell lines HepG2 and Hep3B were purchased from American Type Culture Collection (Manassas, VA). The Huh7 cell line was purchased from RIKEN BioResource Center (Tsukuba, Japan). All cells were cultured in high-glucose DMEM supplemented with $1 \%$ penicillin/streptomycin, $1 \%$ L-glutamine, and $10 \%$ fetal bovine serum (Omega Scientific, Tarzana, CA). All cells were maintained in a 5\% $\mathrm{CO}_{2}$ humidified atmosphere at $37^{\circ} \mathrm{C}$. 


\section{Transient transfection and luciferase reporter gene assays}

The generation of the pGL4-SHP-TK promoter luciferase reporter was described in detail previously (Li et al., 2010). Briefly, the downstream regulatory region of the $\mathrm{NrOb2}$ gene, from +3639 to +4516 relative to the transcription start site, was amplified from mouse genomic DNA by PCR using pairs of primers containing XhoI and BglII restriction enzyme sites, respectively. The PCR product was subcloned upstream of the luciferase gene into the firefly luciferase pGL4-TK vector (Promega, Madison, WI) and was named pGL4-SHP-TK reporter vector. The sequence of the construct was confirmed by DNA sequencing. HepG2 cells were seeded in a 96-well plate and grown to $90 \%$ confluency prior to transient transfection with plasmids consisting of PGL4-SHP-TK reporter gene, pCMV-ICIS human FXR (Open Biosystems, Huntsville, AL), pSG5 human RXR $\alpha$ (Stratagene, La Jolla, CA), and pCMV-renilla luciferase vector (Promega, Madison, WI). Transient transfection was carried out according to the manufacturer's instructions using TurboFect in vitro Transfection Reagent (Fermentas, Glen Burnie, MD). To screen for plant compounds that activate FXR, cells were treated with $0.1 \%$ DMSO (negative control), $1 \mu \mathrm{M} \mathrm{GW} 4064$ (positive control), or various testing compounds at indicated concentrations five hours after transfection. To test the effects of EGCG on GW4064 or CDCA activation of FXR, cells were treated five hours after transfection with $500 \mathrm{nM}$ GW4064 or $100 \mu \mathrm{M}$ CDCA in the absence or presence of increasing concentrations of EGCG $(0$ to $100 \mu \mathrm{M})$ or $0.1 \%$ DMSO as a negative control. Thirty-six hours after treatment, firefly luciferase and renilla luciferase activities were quantified using the Dual-Glo Luciferase Kit (Promega, Madison, WI) in a Synergy-II HT plate reader (Bio-Tek Instruments, Inc., Winooski, VT). The firefly luciferase activity value was normalized as a ratio to that of renilla luciferase and expressed as fold over the pGL4-SHP-TK vector control. For plant compound screening, the data were presented as an average of three assays. For the dose response of ECG, EGC, and EGCG, the data were presented as an average of six wells. For the activation effects of EGCG combined with GW4064 or CDCA on FXR, the data were also presented as an average of six wells. All experiments were repeated at least twice.

\section{FXR-mediated co-activator recruitment assay}

Time-resolved fluorescence resonance transfer (TR-FRET) hFXR coactivator recruitment assays were performed according to the manufacturer's instructions (Invitrogen) with minor modifications. Briefly, the assays were performed in 384-well low volume (20 $\mu \mathrm{l}$ per well) solid black plates with $5 \mathrm{nM}$ GST-FXR ligand-binding domain (LBD), $500 \mathrm{nM}$ fluorescentSRC2-2, $5 \mathrm{nM}$ terbium-labeled anti-GST antibody and a test compound at various concentrations. A potent FXR agonist, GW4064, and DMSO were included in assays as positive and negative controls, respectively. The DMSO concentration was $1 \%$ in all assay wells.

In the reaction mixture containing GW4064, GST-FXR forms a complex with the terbiumlabeled anti-GST antibody and co-activator peptide, fluorescent-SRC2-2. Excitation of terbium using a 340-nm excitation filter results in an energy transfer from terbium to the fluorophore of the labeled co-activator peptide. This energy transfer is detected by an increase in fluorescence emission of the labeled co-activator peptide at $520 \mathrm{~nm}$ and a decrease in fluorescence emission of terbium at $495 \mathrm{~nm}$. The FRET ratio was calculated by dividing the emission signal at $520 \mathrm{~nm}$ by the emission signal at $495 \mathrm{~nm}$. In the absence of a FXR agonist or addition of a FXR antagonist, GST-FXR fails to recruit the co-activator fluorescent-SRC2-2 causing a decrease of the FRET ratio. The reactions were incubated at $25^{\circ} \mathrm{C}$ for 1 hour before measuring the fluorescent emission of each well at 495 and $520 \mathrm{~nm}$ using a 340-nm excitation filter, $100-\mu$ s delay time, and $200-\mu$ s integration time on a PHERAStar plate reader (BMG Labtech, Durham, NC). The FRET ratios were normalized so $100 \%$ activation and $0 \%$ activation represents the activity of GW4064 at $100 \mu \mathrm{M}$ and 0 
$\mu \mathrm{M}$, respectively. The curve-fitting software GraphPad Prism 4.0 was used to generate the curves and determine the $\mathrm{EC}_{50}$ or $\mathrm{IC}_{50}$ values. The potent $\mathrm{FXR}$ agonist $\mathrm{GW} 4064$ has an $\mathrm{EC}_{50}$ of $8.01 \mathrm{nM}$ in this assay.

\section{Animals and treatments}

Wild-type (WT) and FXR-knockout (KO) male mice in C57BL/6J genetic background were used in this study (8-10 weeks old, $\mathrm{n}=5-6$ per group). All mice were housed in pathogenfree animal facilities under a standard 12-h light/dark cycle with access to regular rodent chow and autoclaved tap water ad libitum. The study was carried out in strict accordance with the recommendations in the Guide for the Care and Use of Laboratory Animals of the National Institute of Health. All protocols and procedures were approved by the University of Kansas Medical Center Animal Care and Use Committee. The protocol number approved for this study was 2010-1947. EGCG was dissolved in $0.9 \%$ saline at $10 \mathrm{mg} / \mathrm{ml}$ or $2.5 \mathrm{mg} / \mathrm{ml}$ and was administered twice to mice either orally (P.O.) at $100 \mathrm{mg} / \mathrm{kg}$ or intraperitoneally (I.P.) at $25 \mathrm{mg} / \mathrm{kg}$. The first dose was administered at $7 \mathrm{pm}$ followed by a second dose at 7 am the next day. The control groups were treated with $0.9 \%$ saline. Two hours after the second treatment, blood was collected, and livers, small intestines, and kidneys were removed. Ileums were flushed with 1X Phosphate Buffered Saline (PBS) buffer. All tissues were snap-frozen in liquid nitrogen and stored at $-80{ }^{\circ} \mathrm{C}$ before further analysis.

\section{Determination of serum alanine aminotransferase (ALT) activity}

Blood samples were collected in microtainer serum separator tubes (BD Biosciences, San Jose, CA) and allowed to clot at room temperature for $30 \mathrm{~min}$ before centrifugation at 8,000 $\times g$ and $4{ }^{\circ} \mathrm{C}$ for $15 \mathrm{~min}$ for serum collection. Serum was stored at $-80^{\circ} \mathrm{C}$ until analysis. The kit for analyzing serum ALT activity was obtained from Pointe Scientific (Canton, MI). All measurements were performed according to the manufacturer's instructions.

\section{RNA isolation and quantitative real-time PCR (Q-PCR)}

For in vitro study, HepG2, Hep3B, and Huh7 cells were grown to $80 \%$ confluency before treatment. To test the effect of ECG, EGC or EGCG on the expression of FXR target genes, HepG2 cells were treated with $10 \mu \mathrm{M}$ of each catechin for 24 hours. To test a dose response effect of EGCG on FXR target gene expression, HepG2, Hep3B, and Huh7 cells were treated with increasing concentrations of EGCG for 24 hours. To test the effect of EGCG on the expression of FXR target genes in the presence of GW4064 or CDCA, cells were treated with EGCG or EGCG combined with GW4064 or CDCA for 24 hours. Total RNA was extracted from treated cells using Trizol reagent (Invitrogen, Carlsbad, CA) according to the manufacturer's instructions. The concentration of total RNA was determined by spectrophotometry, and RNA integrity was confirmed by MOPS gel electrophoresis. The mRNA expression levels of FXR and its target genes small heterodimer partner (SHP), organic solute transporter $\alpha(\mathrm{OST} \alpha)$, organic solute transporter $\beta(\mathrm{OST} \beta)$, and bile salt efflux pump (BSEP) were quantified by Q-PCR using SYBR green chemistry, and results were normalized to GAPDH RNA levels. For in vivo studies, frozen livers, ileums, and kidneys collected from mice treated with vehicle or EGCG were used to isolate total RNA. The mRNA expression levels of Fxr and its target genes Shp, Cyp7al and Bsep in liver and ileum bile acid binding protein (Ibabp) and fibroblast growth factor (Fgfl5) in ileum were quantified by Q-PCR using SYBR green chemistry. Results were normalized to Gapdh RNA levels. The primer sequences used in Q-PCR are presented in supplemental data (Table S1). 


\section{Statistical analysis}

All data were presented as mean \pm SD. All data were analyzed by one-way analysis of variance followed by the Student-Newman-Keuls test. $\mathrm{P}<0.05$ is considered statistically significant.

\section{Results}

\section{Screen of tea preparations for activation of FXR by luciferase assay}

Crude extracts from various tea aqueous extracts were used to screen for FXR modulators by luciferase assay. Most of the crude tea extracts activated FXR, but FXR activation was weak (Figure S1). The major active components in tea are polyphenols with EGCG as the major component followed by EGC, ECG and EC. However, great variations of polyphenols are observed among different types and sources of teas. Therefore, we tested two chemical preparations, A007 (ECG + EGC) and A009 (EGC + EGCG), to determine if a combination of pure tea compounds activates FXR. These Mixtures contained an equal molar concentration of each tea compound. Compared to vehicle control, A007 and A009 both activated FXR 2.6 to 4.8 fold at concentrations of $10 \mu \mathrm{M}$ and $100 \mu \mathrm{M}$, respectively (Figure 2).

\section{Dose response of EGCG, ECG and EGC in FXR activation in luciferase assay}

A dose-response of EGCG, EGC, and ECG in activation of FXR was determined by luciferase assay using increasing concentrations of EGCG, EGC or ECG $(0.01,0.1,1,10$ and $100 \mu \mathrm{M})$. All three chemicals dose-dependently increased the luciferase activity with EGCG $>$ EGC $=$ ECG. The maximum response reached a plateau at $10 \mu \mathrm{M}$ with an approximate 7 to 9-fold increase in luciferase activity (Figure 3A). The $\mathrm{EC}_{50}$ of EGCG for FXR activation was $2.99 \mu \mathrm{M}$ (Figures 3A, B). EGCG-mediated activation of FXR appears to be specific because other nuclear receptors, including pregnane $\mathrm{X}$ receptor (PXR), constitutive androstane receptor (CAR), vitamin D receptor (VDR), retinoic acid receptor alpha $(\mathrm{RXR} \alpha)$ and retinoic acid receptor beta $(\mathrm{RXR} \beta)$, were not activated by EGCG (Figure S2).

\section{Induction of FXR target genes in HepG2 cells by tea catechins}

We then determined whether EGCG, EGC and ECG induce gene expression of the classical FXR target genes SHP, OST $\alpha$ and BSEP in HepG2 cells (Figure S3). SHP is an orphan nuclear receptor, OST $\alpha$ transports bile acids as a heterodimer with OST $\beta$, and BSEP is a bile acid efflux transporter. The expression of these genes is induced by FXR activation via direct binding of FXR to their gene regulatory regions (Cui et al., 2003; Landrier et al., 2006). Similar to the positive control, GW4064, all three catechins increased the mRNA levels of SHP and BSEP, but not OST $\alpha$, at $10 \mu \mathrm{M}$.

\section{EGCG didn't recruit coactivator to FXR, but suppressed GW4064-mediated recruitment of coactivator and FXR transactivation}

To determine whether EGCG activates FXR via coactivator recruitment, a coactivator recruitment assay was performed. The result revealed that although EGCG itself did not recruit the coactivator SRC2 to FXR (Figures 4A), it strongly inhibited the GW4064mediated recruitment of SRC2 to FXR with an $\mathrm{IC}_{50}$ of $1 \mu \mathrm{M}$ (Figures $4 \mathrm{~A}$ ). Guggulsterone is a known FXR partial agonist that has also been reported to function as an antagonist in coactivator recruitment (Cui et al., 2003). Guggulsterone inhibited 50\% of GW4064mediated coactivator recruitment at $86 \mu \mathrm{M}$, which was significantly less potent than EGCG (Figure S4). However, the ability of guggulsterone alone to induce coactivator recruitment was higher than that of EGCG alone (Figures 4A and Figure S4), suggesting that EGCG and 
guggulsterone might represent two unique classes of FXR modulators. Luciferase assays were then used to further determine if EGCG inhibits other agonists' activation of FXR. HepG2 cells were treated with the known FXR agonists GW4064 (500 nM) or CDCA (100 $\mu \mathrm{M})$ in the absence or presence of increasing concentrations of EGCG. Although treatment with EGCG alone dose-dependently increased FXR activity, it partially inhibited activation of FXR by GW4064 or CDCA in a dose dependent manner (Figure 4B). FXR activation by GW4064 or CDCA was reduced $35 \%$ and $48 \%$ by $100 \mu \mathrm{M}$ EGCG, respectively. According to these data, EGCG behaves as a unique FXR modulator which can suppress the activity of other FXR agonists.

To further confirm that EGCG is an activator of FXR with antagonistic effects on other FXR agonists, the effects of EGCG on FXR target gene expression in the presence of GW4064 or CDCA were determined by measuring mRNA levels in HepG2, Hep3B, and Huh7 cells. GW4064 and CDCA strongly induced mRNA expression of FXR target genes in all three cell lines. When cells were co-treated with increasing concentrations of EGCG and GW4064 or CDCA, mRNA levels of FXR target genes, OST $\beta$ and BSEP, were dose-dependently decreased in HepG2 cells compared to treatment with GW4064 or CDCA alone (Figure 5). In addition, OST $\beta$ was dose-dependently decreased in Hep3B and Huh7 cells (Figure S5, S6). Furthermore, FXR and its target genes SHP, OST $\alpha$, OST $\beta$ and BSEP were all decreased when co-treated with $100 \mu \mathrm{M}$ of EGCG and GW4064 or CDCA in HepG2 cells (Figure 5). Similar results were also found in Hep3B and Huh7 cells (Figure S5, S6).

\section{Activation of FXR by EGCG in vivo}

FXR activation in liver and small intestine by acute EGCG treatment was evaluated in WT and FXR-KO mice. Higher concentrations of EGCG are known to be hepatotoxic (Goodin and Rosengren, 2003; Lambert et al., 2010), so we used lower concentrations of EGCG in this study to avoid liver toxicity. There was no change in the serum activity of ALT with EGCG treatment, which confirmed that there was no obvious liver toxicity associated with the EGCG dose selected (Figure 6).

EGCG treatment administered by I.P. or P.O. did not alter mRNA expression levels of FXR target genes Shp, Bsep, or Cyp7al in the liver (Figure S7). In contrast, I.P. administration of EGCG increased Shp mRNA levels by 2-fold, and P.O. administration of EGCG induced mRNA levels of Shp by 12 -fold and Fgfl5 by 2-fold in the small intestine of WT mice, but not of FXR-KO mice (Figure 7). Unlike treatment with the synthetic FXR agonist GW4064, which strongly induces expression of all FXR target genes in intestine (Kim et al., 2007a), EGCG selectively induced expression of Shp and Fgf15, but not Ibabp (Figure 7). In the kidney, neither I.P. nor P.O. administration of EGCG altered mRNA expression levels of Fxr or its target gene Shp (Figure S8).

\section{Discussion}

The current study identified unique FXR modulators from tea. FXR was activated by tea catechins EGCG, EGC and ECG in a dose-dependent manner as shown by luciferase assay. Activation of FXR by tea catechins induced FXR target gene expression in vitro. However, EGCG by itself did not recruit coactivators to FXR; it instead inhibited FXR agonistmediated recruitment of coactivators and transactivation of FXR. Notably, activation of FXR by EGCG in vivo appears to be tissue-specific because only intestinal, but not hepatic, FXR was activated by EGCG. Furthermore, FXR was activated by EGCG in the small intestine, but only a subset of FXR target genes was induced.

Our results identified that catechins are natural FXR modulators. There are currently few reports on FXR activation by natural plant compounds. The only compound extracted from 
plants reported to activate FXR is cafestol, a diterpene present in unfiltered coffee brews (Ricketts et al., 2007). Cafestol is not specific for FXR activation because it also activates PXR. In this study, we determined that EGCG activates FXR without activating other nuclear receptors including RXR $\alpha, \mathrm{RXR} \beta, \mathrm{CAR}$, and VDR.

In comparison with FXR agonists GW4064 and CDCA, the potency of EGCG in activation of FXR is modest. The $\mathrm{EC}_{50}$ of two FXR full agonists, CDCA and GW4064, in activating human FXR are $10 \mu \mathrm{M}$ and $15 \mathrm{nM}$, respectively. The $\mathrm{EC}_{50}$ of EGCG to activate human FXR in luciferase assay is $2.99 \mu \mathrm{M}$. EGCG is able to activate FXR in vitro at a range of 1 to $10 \mu \mathrm{M}$. It is reported that in human and mouse plasma, EGCG concentration may reach 1.3 $\mu \mathrm{M}$ and $13.6 \mu \mathrm{M}$, respectively (Van Amelsvoort et al., 2001; Lambert et al., 2003). No data are available for tissue concentrations of various catechins in humans after tea consumption, but in mice, the concentrations of EGCG may reach $3.56 \mathrm{nMol} / \mathrm{g}$ in liver and $2.4 \mathrm{nMol} / \mathrm{g}$ in intestine (Lambert et al., 2003), which suggests that FXR should be activated by EGCG in vivo.

Furthermore, we found that EGCG acts as a unique modulator of FXR. EGCG alone is a FXR activator. However, in the presence of other potent agonists, such as GW4064 or CDCA, EGCG acts as an antagonist of FXR activation. EGCG dose-dependently inhibited GW4064-mediated coactivator recruitment to FXR (Figure 4A). In addition, EGCG inhibited FXR agonist-mediated induction of FXR target genes in HepG2 cells (Figure 4B). Guggulsterone, which is extracted from the Commiphora mukul tree, has been reported to function as a FXR partial agonist (Cui et al., 2003; Deng et al., 2007). Similar to EGCG, guggulsterone alone activated FXR but suppressed coactivator recruitment to FXR induced by other FXR agonists. However, while EGCG inhibited the transactivity of other FXR agonists, guggulsterone paradoxically enhanced other agonists' action in FXR target gene induction in vitro (Cui et al., 2003). This data suggests that EGCG and guggulsterone represent two different classes of FXR modulators.

Our study also identified EGCG as a tissue- and gene-specific FXR modulator in vivo. EGCG only activated intestinal FXR without affecting the expression of FXR target genes in the liver. In addition, EGCG induced expression of some, but not all, FXR target genes in the intestine including both Shp and Fgf15, but not Ibabp. The reason that EGCG tissuespecifically activates FXR may be due to rapid metabolism and elimination of EGCG from the liver or interaction with endogenous FXR ligands. Moreover, the low bioavailability and poor stability of EGCG may also contribute to the tissue-specific activation of FXR. Studies have shown that following intravenous administration, EGCG is rapidly conjugated and eliminated in the liver (Lambert et al., 2003) with glucuronidation as the most abundant pathway in EGCG metabolism (Lambert et al., 2003; Lu et al., 2003). We found that a high concentration of EGCG $(100 \mu \mathrm{M})$ suppresses FXR target genes in the presence of a potent FXR agonist in vitro (Figure 5). However, it is hard to reach this concentration in vivo due to fast metabolism of EGCG. Furthermore, EGCG can activate intestinal FXR by P.O. administration of $100 \mathrm{mg} / \mathrm{kg}$ in mice, but this concentration is too high to achieve in humans by drinking green tea only. A combination of consuming green tea in the diet with taking EGCG supplements is a likely approach to increase the dose of EGCG in humans.

In the current study, our results suggest that EGCG functions as a unique FXR modulator. However, EGCG showed inhibitory effects on FXR transactivation in the presence of potent FXR agonists, CDCA and GW4064 (Figure 4B). Thus it is possible that in liver, EGCG functions as a FXR antagonist in the presence of high concentrations of bile acids. In addition, it may function as a FXR agonist in intestine, which contains lower levels of bile acids. 
Tea and tea catechins are well-known for their beneficial effects in improving digestion and chemoprevention of cancers, especially in the oral cavity and intestinal tract where higher EGCG concentrations are achieved (Deng et al., 2007; Yang et al., 2007). The mechanisms of cancer prevention of EGCG may be associated with decreased cell proliferation and increased apoptosis, specifically with decreased nuclear levels of $\beta$-catenin (Yang et al., 2009). FXR deficiency in mice leads to increased colon cancer incidence (Maran et al., 2009), and the expression and function of FXR is markedly reduced in human colorectal cancers (De Gottardi et al., 2004). FXR may modulate inflammatory responses, cell proliferation and apoptosis in liver, intestine and breast (Smith et al.; Kim et al., 2007b; Modica et al., 2008; Journe et al., 2009; Maran et al., 2009). Therefore, maintaining FXR function in intestine may help prevent or reduce intestinal tumorigenesis. Although not yet tested, FXR activation may represent a mechanism responsible for the effect of tea in reducing gastrointestinal tract cancer risk.

In summary, tea catechins, especially EGCG, are FXR selective modulators. EGCG is the major polyphenol in green tea, and it functions as a unique modulator of FXR. EGCG moderately activates FXR by itself, but inhibits transactivation of FXR by other agonists. Oral administration of low concentrations of EGCG activates FXR to induce a subset of FXR target genes in the small intestine but does not induce FXR target gene expression in the liver. Activation of FXR may represent a novel mechanism of EGCG in improving intestinal health.

\section{Supplementary Material}

Refer to Web version on PubMed Central for supplementary material.

\section{Acknowledgments}

Funding

This study was supported by the National Institutes of Health funding [Grants DK081343 (GLG), GM086415 (TC) and P20-RR021940 (GLG)]; and KUMC Endowment fund (GLG). The funders had no role in study design, data collection and analysis, decision to publish, or preparation of the manuscript.

The authors would like to appreciate the support from Ms. Melinda Broward for her excellence in coordinating the studies. The authors would like to thank Ms. Noriko Esterly, and Drs. Gemma O'Donnell and Huaping Zhang, as well as Dr. Bruno Hagenbuch and Ms. Megan Ruth for their participation and discussion in the study. We would like to thank Satyanarayana R. Pondugula and Alexander A. Tong for technical assistance.

\section{List of Abbreviations}

$\begin{array}{ll}\text { ALT } & \text { alanine aminotransferase } \\ \text { BSEP } & \text { bile salt efflux pump } \\ \text { CAR } & \text { constitutive androstane receptor } \\ \text { CDCA } & \text { chenodeoxycholic acid } \\ \text { EC } & (-) \text {-epicatechin } \\ \text { ECG } & (- \text { )-epicatechin-3-gallate } \\ \text { EGC } & (-) \text {-epigallocatechin } \\ \text { EGCG } & (- \text { )-epigallocatechins-3-gallate } \\ \text { Fgf15 } & \text { fibroblast growth factor }\end{array}$




$\begin{array}{ll}\text { FXR } & \text { farnesoid X receptor } \\ \text { Ibabp } & \text { ileum bile acid binding protein } \\ \text { I.P } & \text { intraperitoneally } \\ \text { OST } \boldsymbol{\alpha} & \text { organic solute transporter } \alpha \\ \text { P.O } & \text { orally } \\ \text { Q-PCR } & \text { quantitative real-time PCR } \\ \text { RXRo } & \text { retinoic acid receptor alpha } \\ \text { RXRß } & \text { retinoic acid receptor beta } \\ \text { SHP } & \text { small heterodimer partner } \\ \text { TR-FRET } & \text { time-resolved fluorescence resonance transfer } \\ \text { PXR } & \text { pregnane X receptor } \\ \text { VDR } & \text { vitamin D receptor }\end{array}$

\section{References}

Cabrera C, Artacho R, Gimenez R. Beneficial effects of green tea--a review. J Am Coll Nutr. 2006; 25:79-99. [PubMed: 16582024]

Cariou B, van Harmelen K, Duran-Sandoval D, van Dijk T, Grefhorst A, Bouchaert E, Fruchart JC, Gonzalez FJ, Kuipers F, Staels B. Transient impairment of the adaptive response to fasting in FXRdeficient mice. FEBS Lett. 2005; 579:4076-4080. [PubMed: 16023103]

Chyu KY, Babbidge SM, Zhao X, Dandillaya R, Rietveld AG, Yano J, Dimayuga P, Cercek B, Shah PK. Differential effects of green tea-derived catechin on developing versus established atherosclerosis in apolipoprotein E-null mice. Circulation. 2004; 109:2448-2453. [PubMed: 15136500]

Crawley ML. Farnesoid X receptor modulators: a patent review. Expert Opin Ther Pat. 2010; 20:1047-1057. [PubMed: 20569093]

Cui J, Huang L, Zhao A, Lew JL, Yu J, Sahoo S, Meinke PT, Royo I, Pelaez F, Wright SD. Guggulsterone is a farnesoid $\mathrm{X}$ receptor antagonist in coactivator association assays but acts to enhance transcription of bile salt export pump. J Biol Chem. 2003; 278:10214-10220. [PubMed: 12525500]

De Gottardi A, Touri F, Maurer CA, Perez A, Maurhofer O, Ventre G, Bentzen CL, Niesor EJ, Dufour JF. The bile acid nuclear receptor FXR and the bile acid binding protein IBABP are differently expressed in colon cancer. Dig Dis Sci. 2004; 49:982-989. [PubMed: 15309887]

Deng R, Yang D, Radke A, Yang J, Yan B. The hypolipidemic agent guggulsterone regulates the expression of human bile salt export pump: dominance of transactivation over farsenoid $\mathrm{X}$ receptormediated antagonism. J Pharmacol Exp Ther. 2007; 320:1153-1162. [PubMed: 17135343]

Dona M, Dell'Aica I, Calabrese F, Benelli R, Morini M, Albini A, Garbisa S. Neutrophil restraint by green tea: inhibition of inflammation, associated angiogenesis, and pulmonary fibrosis. J Immunol. 2003; 170:4335-4341. [PubMed: 12682270]

Frei B, Higdon JV. Antioxidant activity of tea polyphenols in vivo: evidence from animal studies. J Nutr. 2003; 133:3275S-3284S. [PubMed: 14519826]

Gadaleta RM, van Mil SW, Oldenburg B, Siersema PD, Klomp LW, van Erpecum KJ. Bile acids and their nuclear receptor FXR: Relevance for hepatobiliary and gastrointestinal disease. Biochim Biophys Acta. 2010; 1801:683-692. [PubMed: 20399894]

Goodin MG, Rosengren RJ. Epigallocatechin gallate modulates CYP450 isoforms in the female SwissWebster mouse. Toxicol Sci. 2003; 76:262-270. [PubMed: 14600287]

Jian L, Xie LP, Lee AH, Binns CW. Protective effect of green tea against prostate cancer: a casecontrol study in southeast China. Int J Cancer. 2004; 108:130-135. [PubMed: 14618627] 
Journe F, Durbecq V, Chaboteaux C, Rouas G, Laurent G, Nonclercq D, Sotiriou C, Body JJ, Larsimont D. Association between farnesoid X receptor expression and cell proliferation in estrogen receptor-positive luminal-like breast cancer from postmenopausal patients. Breast Cancer Res Treat. 2009; 115:523-535. [PubMed: 18563553]

Kim I, Ahn SH, Inagaki T, Choi M, Ito S, Guo GL, Kliewer SA, Gonzalez FJ. Differential regulation of bile acid homeostasis by the farnesoid X receptor in liver and intestine. J Lipid Res. 2007a; 48:2664-2672. [PubMed: 17720959]

Kim I, Morimura K, Shah Y, Yang Q, Ward JM, Gonzalez FJ. Spontaneous hepatocarcinogenesis in farnesoid X receptor-null mice. Carcinogenesis. 2007b; 28:940-946. [PubMed: 17183066]

Lambert JD, Kennett MJ, Sang S, Reuhl KR, Ju J, Yang CS. Hepatotoxicity of high oral dose (-)epigallocatechin-3-gallate in mice. Food Chem Toxicol. 2010; 48:409-416. [PubMed: 19883714]

Lambert JD, Lee MJ, Lu H, Meng X, Hong JJ, Seril DN, Sturgill MG, Yang CS. Epigallocatechin-3gallate is absorbed but extensively glucuronidated following oral administration to mice. J Nutr. 2003; 133:4172-4177. [PubMed: 14652367]

Landrier JF, Eloranta JJ, Vavricka SR, Kullak-Ublick GA. The nuclear receptor for bile acids, FXR, transactivates human organic solute transporter-alpha and -beta genes. Am J Physiol Gastrointest Liver Physiol. 2006; 290:G476-485. [PubMed: 16269519]

Li G, Thomas AM, Hart SN, Zhong X, Wu D, Guo GL. Farnesoid X receptor activation mediates head-to-tail chromatin looping in the NrOb2 gene encoding small heterodimer partner. Mol Endocrinol. 2010; 24:1404-1412. [PubMed: 20444884]

Lu H, Meng X, Li C, Sang S, Patten C, Sheng S, Hong J, Bai N, Winnik B, Ho CT, Yang CS. Glucuronides of tea catechins: enzymology of biosynthesis and biological activities. Drug Metab Dispos. 2003; 31:452-461. [PubMed: 12642472]

Ma K, Saha PK, Chan L, Moore DD. Farnesoid X receptor is essential for normal glucose homeostasis. J Clin Invest. 2006; 116:1102-1109. [PubMed: 16557297]

Makishima M, Okamoto AY, Repa JJ, Tu H, Learned RM, Luk A, Hull MV, Lustig KD, Mangelsdorf DJ, Shan B. Identification of a nuclear receptor for bile acids. Science. 1999; 284:1362-1365. [PubMed: 10334992]

Maran RR, Thomas A, Roth M, Sheng Z, Esterly N, Pinson D, Gao X, Zhang Y, Ganapathy V, Gonzalez FJ, Guo GL. Farnesoid X receptor deficiency in mice leads to increased intestinal epithelial cell proliferation and tumor development. J Pharmacol Exp Ther. 2009; 328:469-477. [PubMed: 18981289]

Modica S, Murzilli S, Salvatore L, Schmidt DR, Moschetta A. Nuclear bile acid receptor FXR protects against intestinal tumorigenesis. Cancer Res. 2008; 68:9589-9594. [PubMed: 19047134]

Raederstorff DG, Schlachter MF, Elste V, Weber P. Effect of EGCG on lipid absorption and plasma lipid levels in rats. J Nutr Biochem. 2003; 14:326-332. [PubMed: 12873714]

Ricketts ML, Boekschoten MV, Kreeft AJ, Hooiveld GJ, Moen CJ, Muller M, Frants RR, Kasanmoentalib S, Post SM, Princen HM, Porter JG, Katan MB, Hofker MH, Moore DD. The cholesterol-raising factor from coffee beans, cafestol, as an agonist ligand for the farnesoid and pregnane X receptors. Mol Endocrinol. 2007; 21:1603-1616. [PubMed: 17456796]

Rizzo G, Renga B, Mencarelli A, Pellicciari R, Fiorucci S. Role of FXR in regulating bile acid homeostasis and relevance for human diseases. Curr Drug Targets Immune Endocr Metabol Disord. 2005; 5:289-303. [PubMed: 16178789]

Setiawan VW, Zhang ZF, Yu GP, Lu QY, Li YL, Lu ML, Wang MR, Guo CH, Yu SZ, Kurtz RC, Hsieh CC. Protective effect of green tea on the risks of chronic gastritis and stomach cancer. Int $\mathbf{J}$ Cancer. 2001; 92:600-604. [PubMed: 11304697]

Sinal CJ, Tohkin M, Miyata M, Ward JM, Lambert G, Gonzalez FJ. Targeted disruption of the nuclear receptor FXR/BAR impairs bile acid and lipid homeostasis. Cell. 2000; 102:731-744. [PubMed: 11030617]

Smith DL, Keshavan P, Avissar U, Ahmed K, Zucker SD. Sodium taurocholate inhibits intestinal adenoma formation in APCMin/+ mice, potentially through activation of the farnesoid X receptor. Carcinogenesis. 31:1100-1109. [PubMed: 20194350] 
Van Amelsvoort JM, Van Hof KH, Mathot JN, Mulder TP, Wiersma A, Tijburg LB. Plasma concentrations of individual tea catechins after a single oral dose in humans. Xenobiotica. 2001; 31:891-901. [PubMed: 11780763]

Vavassori P, Mencarelli A, Renga B, Distrutti E, Fiorucci S. The bile acid receptor FXR is a modulator of intestinal innate immunity. J Immunol. 2009; 183:6251-6261. [PubMed: 19864602]

Wu AH, Yu MC, Tseng CC, Hankin J, Pike MC. Green tea and risk of breast cancer in Asian Americans. Int J Cancer. 2003; 106:574-579. [PubMed: 12845655]

Yang CS, Lambert JD, Ju J, Lu G, Sang S. Tea and cancer prevention: molecular mechanisms and human relevance. Toxicol Appl Pharmacol. 2007; 224:265-273. [PubMed: 17234229]

Yang CS, Wang X, Lu G, Picinich SC. Cancer prevention by tea: animal studies, molecular mechanisms and human relevance. Nat Rev Cancer. 2009

Zhang M, Binns CW, Lee AH. Tea consumption and ovarian cancer risk: a case-control study in China. Cancer Epidemiol Biomarkers Prev. 2002; 11:713-718. [PubMed: 12163323]

Zhang Y, Lee FY, Barrera G, Lee H, Vales C, Gonzalez FJ, Willson TM, Edwards PA. Activation of the nuclear receptor FXR improves hyperglycemia and hyperlipidemia in diabetic mice. Proc Natl Acad Sci U S A. 2006; 103:1006-1011. [PubMed: 16410358] 


\section{Highlights}

Epigallocatechin-3-gallate (EGCG) is a unique farnesoid X receptor (FXR) modulator.

EGCG activates FXR by itself, but inhibits FXR transactivation by other agonists.

Low concentration of EGCG activates FXR in mouse intestine but not liver.

EGCG activates FXR to induce a subset of FXR target genes in mouse intestine. 


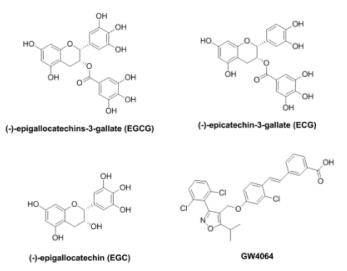

Figure 1. Chemical structure of EGCG, EGC, and ECG, in comparison to a known FXR agonist, GW4064

Chemical structure of tea catechins, (-)-epigallocatechins-3-gallate (EGCG), (-)epigallocatechin (EGC), (-)-epicatechin-3-gallate (ECG), and GW4064. 


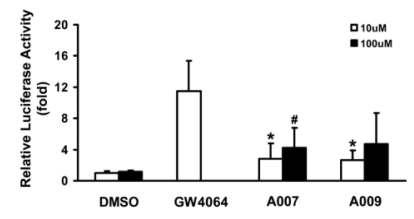

Figure 2. Screen of tea preparations for modulation of FXR activity, determined by luciferase assay

HepG2 cells were transfected with various plasmids indicated in the Methods. Five hours after transfection, cells were treated for 36 hours with different tea compound mixtures at two concentrations, 10 and $100 \mu \mathrm{M}$. The two mixtures A007 (ECG + EGC) and A009 (EGC + EGCG) contain equal molar concentrations of individual tea catechins. GW4064 at $1 \mu \mathrm{M}$ was used as a positive control, and 0.1\% DMSO was used as a negative control. The cells were lysed, and luciferase activities were determined to indicate FXR activation. An asterisk represents $\mathrm{P}<0.05$ between $10 \mu \mathrm{M}$ treatment and DMSO group; a pound sign represents $\mathrm{P}<$ 0.05 between $100 \mu \mathrm{M}$ treatment and DMSO group. 


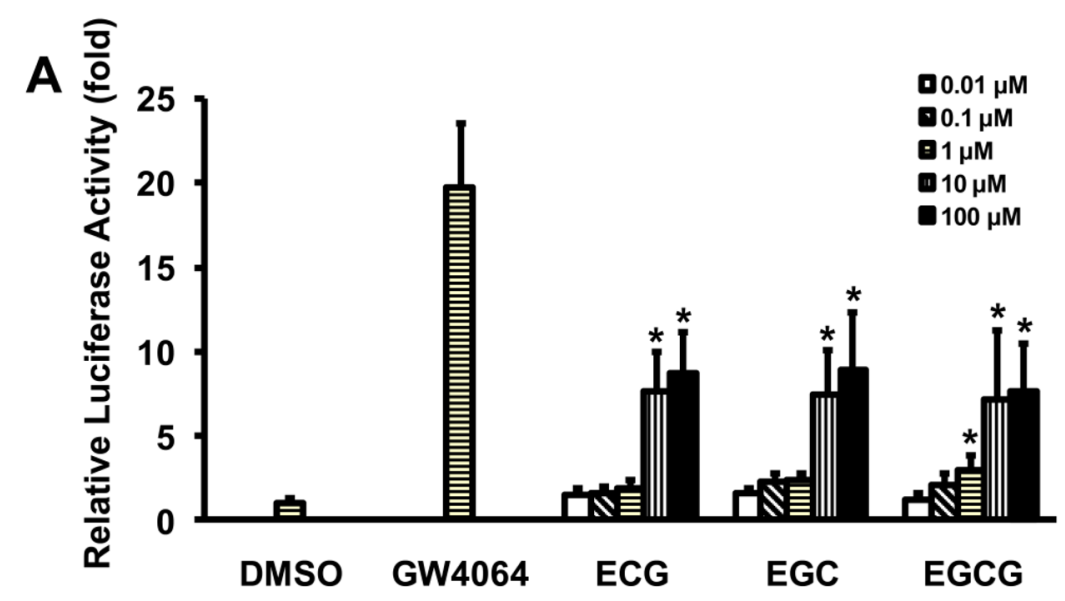

B

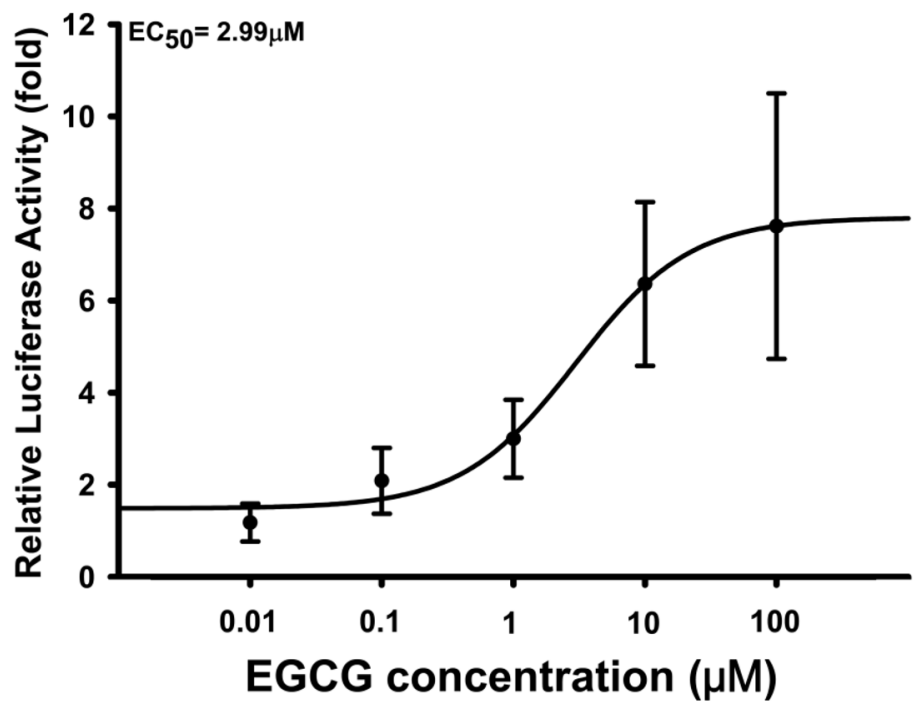

Figure 3. Dose response of catechins in activation of FXR, determined by luciferase assay HepG 2 cells were transfected with various plasmids indicated in the Methods. Five hours after transfection, cells were treated with $1 \mu \mathrm{M} \mathrm{GW} 4064$ (positive control), $0.1 \%$ DMSO (negative control), or increasing concentrations of catechins, from $0.01 \mu \mathrm{M}$ to $100 \mu \mathrm{M}$, for 36 hours before measuring luciferase activity. A, Dose-dependent activation of FXR by ECG, EGC, or EGCG. An asterisk indicates $\mathrm{P}<0.05$ versus $0.01 \mu \mathrm{M}$ treatment group. B, The $\mathrm{EC}_{50}$ of EGCG in activating FXR is $2.99 \mu \mathrm{M}$. 
A
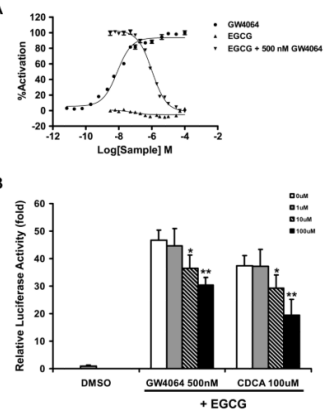

Figure 4. The effect of EGCG on both basal and GW4064-mediated coactivator recruitment to and transactivation of FXR

A, The fluorescence resonance transfer (FRET) hFXR coactivator recruitment assays were performed as described in the Methods. The $\mathrm{x}$ axis represents the log of increasing concentrations of EGCG alone, GW4064, or EGCG combined with 500 nM of GW4064. The y axis represents relative FXR coactivator recruitment activity. FRET ratios were normalized so $100 \%$ activation and $0 \%$ activation represent the activity of GW4064 at 100 $\mu \mathrm{M}$ and $0 \mu \mathrm{M}$, respectively. The results showed that (1) EGCG alone did not lead to coactivator recruitment, and (2) EGCG inhibited GW4064-mediated recruitment of coactivator to FXR in a dose responsive manner. The $\mathrm{IC}_{50}$ of EGCG is $\sim 1 \mu \mathrm{M}$.

B, Effects of EGCG on other agonists (GW4064 and CDCA) transactivation of FXR as determined by luciferase assay. HepG2 cells were transfected with various plasmids indicated in the Methods. Five hours after transfection, cells were treated with $0.1 \%$ DMSO as a negative control or with increasing concentrations of EGCG, from $0 \mu \mathrm{M}$ to $100 \mu \mathrm{M}$, combined with $500 \mathrm{nM}$ GW4064 or $100 \mu \mathrm{M}$ CDCA for 36 hours before measuring luciferase activity. An asterisk indicates $\mathrm{P}<0.05$ between the combined treatment and the no EGCG treatment group. Double asterisks indicate $\mathrm{P}<0.01$ between the combined treatment and the no EGCG treatment group. 

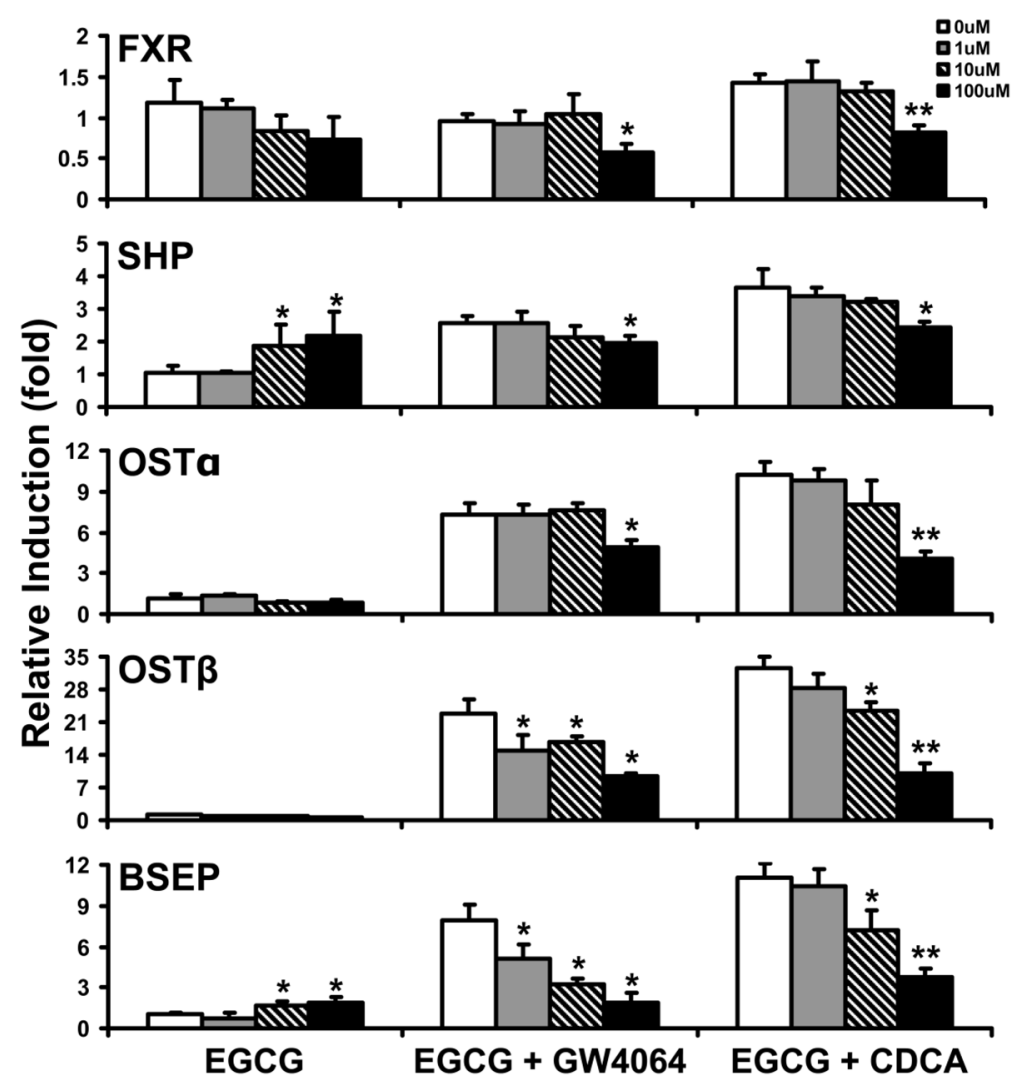

Figure 5. Effects of EGCG on FXR target gene induction by GW4064 and CDCA in HepG2 cells HepG2 cells were treated with $500 \mathrm{nM}$ GW4064 or $100 \mu \mathrm{M}$ CDCA for 24 hours in the absence or presence of increasing concentrations of EGCG $(1,10$ and $100 \mu \mathrm{M})$. The mRNA levels of FXR, SHP, OST $\alpha$, OST $\beta$ and BSEP were determined by Q-PCR with $n=3$ per group. The results for each gene were normalized to vehicle control. An asterisk represents $\mathrm{P}<0.05$ between the treatment and no EGCG treatment group. Double asterisks indicate $\mathrm{P}<$ 0.01 between the combined treatment and no EGCG treatment group. 


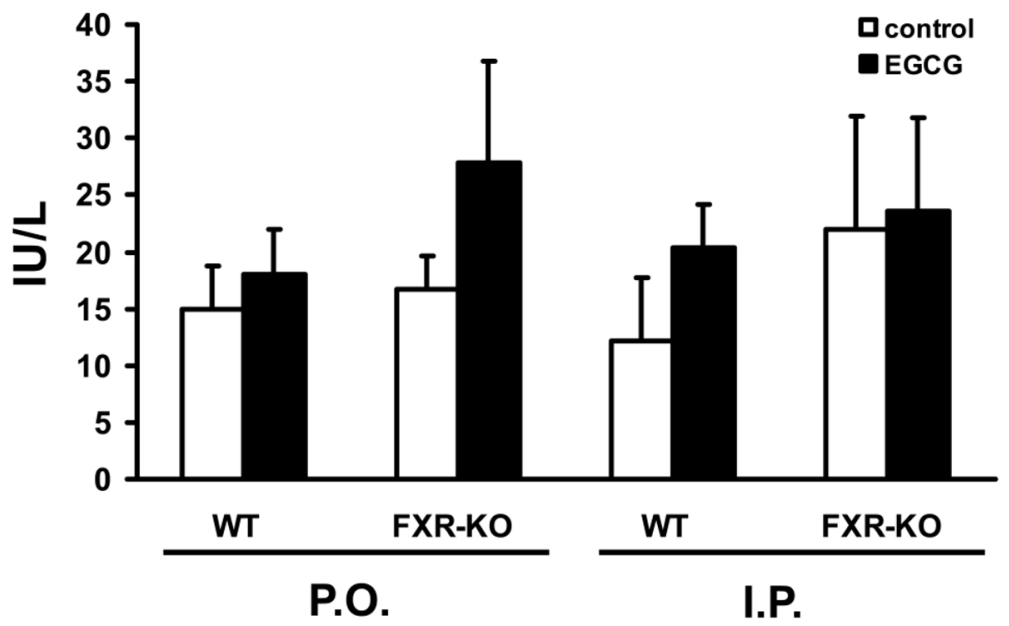

Figure 6. Mouse serum alanine aminotransferase (ALT) levels with EGCG treatment Serum levels of ALT were determined after WT and FXR-KO mice were treated twice in one day with EGCG at $100 \mathrm{mg} / \mathrm{kg}$ for P.O. or at $25 \mathrm{mg} / \mathrm{kg}$ for I.P.. Data are expressed as mean $\pm \mathrm{SD}, \mathrm{n}=5$ mice per group. 


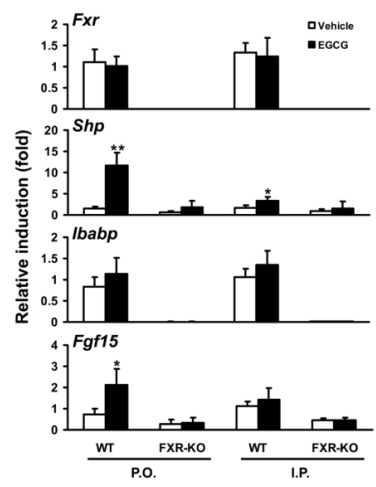

Figure 7. Induction of FXR target genes in ileum of WT and FXR-KO mice following acute EGCG treatment

WT and FXR-KO mice were treated twice in one day with EGCG at $100 \mathrm{mg} / \mathrm{kg}$ for P.O. or at $25 \mathrm{mg} / \mathrm{kg}$ for I.P. The control groups were treated with vehicle. Intestinal mRNA levels of $F x r$, Shp Ibabp, and Fgfl5 were determined by Q-PCR ( $n=5$ mice per group). An asterisk indicates $\mathrm{P}<0.05$ between the treatment and vehicle control group. Double asterisks indicate $\mathrm{P}<0.01$ between the treatment and vehicle control group. 